\title{
Effect and related mechanism of Yinchenhao decoction on mice with lithogenic diet-induced cholelithiasis
}

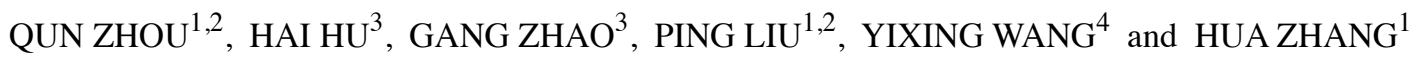 \\ ${ }^{1}$ Institute of Liver Diseases, Shuguang Hospital Affiliated to Shanghai University of Traditional Chinese Medicine, \\ Key Laboratory of Clinical Chinese Medicine, Key Laboratory of Liver and Kidney Diseases of Ministry of Education, \\ Shanghai Key Laboratory of Traditional Chinese Clinical Medicine; ${ }^{2}$ Institute of Interdisciplinary Integrative Medicine \\ Research, Shanghai University of Traditional Chinese Medicine, Shanghai 201203; ${ }^{3}$ Department of Cholelithiasis; \\ ${ }^{4}$ Department of Traditional Chinese Medicine, East Hospital Affiliated to Tongji University, Shanghai 200120, P.R. China
}

Received February 27, 2020; Accepted July 27, 2020

DOI: $10.3892 /$ etm.2021.9747

\begin{abstract}
The aim of the present study was to investigate the effects and the underlying mechanisms of Yinchenhao Decoction (YCHD), a traditional Chinese medicine formulation, on C57BL/6 mice with lithogenic diet (LD)-induced cholelithiasis. The condition of cholelithiasis was evaluated using a six-level criteria. Levels of alanine aminotransferase (ALT), alkaline phosphatase (ALP), total cholesterol (TC), low-density lipoprotein cholesterol (LDL-C) in the serum and liver tissue were measured using enzyme colorimetry. Concentrations of TC, phospholipids (PL) and total bile acids (TBA) in the bile were measured to calculate the cholesterol saturation index. Liver histopathology was microscopically observed and mRNA expression levels of ABCG5, ABCG8, SRBI, ABCB4, ABCB11 and NPC1L1 involved in cholesterol metabolism were measured using reverse transcription-quantitative PCR. The results showed that feeding mice the LD induced cholelithiasis, along with abnormal serum biochemical indices and imbalances in biliary cholesterol homeostasis. Increased ALT and ALP levels in the serum and ALT, ALP, TC and LDL-C levels in the serum and liver indicated the existence of hepatocyte injury, which were consistent with the pathological changes. YCHD treatment ameliorated the serum and hepatic biochemical abnormalities
\end{abstract}

Correspondence to: Dr Yixing Wang, Department of Traditional Chinese Medicine, East Hospital Affiliated to Tongji University, 150 Jimo Road, Shanghai 200120, P.R. China

E-mail: wangyixingcn@hotmail.com

Professor Hua Zhang, Institute of Liver Diseases, Shuguang Hospital Affiliated to Shanghai University of Traditional Chinese Medicine, Key Laboratory of Clinical Chinese Medicine, Key Laboratory of Liver and Kidney Diseases of Ministry of Education, Shanghai Key Laboratory of Traditional Chinese Clinical Medicine, 528 Zhangheng Road, Shanghai 201203, P.R. China

E-mail:1nutcmzh@126.com

Key words: cholelithiasis, Yinchenhao decoction, biliary cholesterol supersaturation, cholesterol metabolism and adjusted the biliary imbalance. In addition, elevated expression of ATP-binding cassette subfamily $\mathrm{G}$ member $5 / 8$, scavenger receptor class B type I and Niemann-Pick C1 Like 1 in the liver and small intestine were observed at the onset of cholelithiasis but were reversed by YCHD. Taken together, results from the present study suggest that YCHD ameliorated LD-induced cholelithiasis mice, which may be caused by improvements in biliary cholesterol supersaturation and regulation of cholesterol metabolism.

\section{Introduction}

Cholelithiasis is a prevalent gastrointestinal disease that has a prevalence of $\sim 10-15 \%$ in developed countries and $\sim 13 \%$ in China $(1,2)$. However, this rate is increasing on an annual basis mainly due to dietary and lifestyle changes (3). Cholelithiasis is caused by multiple factors, including cholesterol supersaturation in the bile, abnormal gallbladder function and impairments in enterohepatic bile acid circulation, where cholesterol supersaturation is a necessary condition for the onset of disease (4). Under physiological conditions, relative concentrations of cholesterol, phospholipids and bile acids in bile are regulated in balance. Supersaturation occurs when the levels of cholesterol are too high or when there is an insufficient solubility of phospholipids and bile acids, which in turn affect this dynamic balance (5). Excessive cholesterol accumulation can then form crystals, eventually forming gallstones (6).

Cholesterol metabolism serves a critical role in cholelithiasis. In total, $50 \%$ cholesterol is directly secreted into the bile by the coordinated functions of cholesterol transporters ATP-binding cassette subfamily G member (ABCG) 5/8 (ABCG5/8) and scavenger receptor class B type I (SRBI) (7). ABCG5/8 is a heterodimer that is localized in the canalicular membrane of hepatocytes and is responsible for transporting cholesterol out of hepatocytes, whilst SRBI can transport cholesterol bi-directionally and convert it into bile acid $(8,9)$. The secretion of cholesterol also requires the assistance of bile acids and phospholipids, which are separately mediated by the bile salt export pump ABCB11 and the phospholipid transporter ABCB4 (10). Cholesterol absorption is multifaceted processes that is regulated by a number of factors on the 
enterocyte level. Previous studies have shown that ABCG5 and ABCG8, which are also highly expressed on the apical brush border membranes of enterocytes, can reduce cholesterol absorption and promote the active efflux of cholesterol from the enterocyte into the intestinal lumen for excretion $(11,12)$. Niemann-Pick C1 Like 1 (NPC1L1) is an essential transporter that mediates exogenous cholesterol uptake by the enterocyte (13). The capacity of the small intestine tissue to absorb cholesterol can also significantly affect the concentration of cholesterol in the human blood circulation (14).

Although patients with cholelithiasis are generally asymptomatic, progression of this disease can result in serious consequences. Laparoscopic cholecystectomy is considered to be the gold-standard therapy for patients with symptomatic cholelithiasis, which can reduce pain and produce low rates of recurrence (15). However, this type of surgery is associated with a variety of adverse events, including functional dyspepsia, gastroesophageal reflux disease, postcholecystectomy syndrome and bile duct injury (16). Therefore, alternative treatment approaches remain in demand for patients with cholelithiasis.

Traditional Chinese Medicine (TCM) have been considered for the treatment of cholelithiasis, since it has been reported to effectively discharge gallstones and prevent the recurrence of this condition (17). Yinchenhao decoction (YCHD, Inchin-ko-to or TJ-135 in Japan) is a well-known TCM formulation that was first recorded in the Treatise on Febrile Diseases (Shanghan Lun) by Zhongjing Zhang in 150-215 A.D. and has been widely used for the treatment of hepatic and biliary disorders. This prescription is comprised of three Chinese medicinal herbs: Artemisiae scopariae herba (Yinchen), Gardeniae Fructus (Zhizi) and Radix et Rhizoma Rhei (Dahuang) (18,19). These ingredients exhibit synergistic properties that intensify the therapeutic efficacy of YCHD towards hepatic injury according to a previous biochemical analysis (20). Pharmacological studies have previously indicated that YCHD can inhibit hepatic steatosis, apoptosis, necrosis, anti-inflammation and regulate immunization, in addition to exhibiting choleretic effects (21-24). Previous in vivo experiments have also demonstrated that YCHD exerts beneficial preventative and therapeutic effects against lipid disturbance in rats $(25,26)$. In addition, YCHD has also been revealed to confer potent ameliorative effects on rats with cholestasis, which was associated with its regulatory actions on the expression of metabolic enzymes and transporters including UDP-glucuronosyltransferase 1-A1, multidrug resistance-associated protein 2 , bile salt export pump and organic anion-transporting polypeptide 1a4 in the cholestatic liver (27).

Although YCHD has been applied for centuries for treating cholelithiasis in clinical practice in China, the possible underlying mechanism remains unclear. Therefore, the aim of the present study was to investigate the effects and potential mechanism of YCHD on mice with lithogenic diet (LD)-induced cholelithiasis in vivo, to provide a scientific and objective theoretical basis for clinical treatment using YCHD.

\section{Materials and methods}

Drug preparation. YCHD consists of Artemisiae scopariae herba (27 g), Gardeniae Fructus (6 g), and Radix et Rhizoma Rhei (9 g) (28). The medicinal herbs were obtained from the Chinese Pharmacy at Shuguang Hospital Affiliated to Shanghai University of Traditional Chinese Medicine. The process of extraction was performed according to a previous published patent (patent no. ZL201010501560.7) and article (29). Briefly, herbs were soaked in distilled water (1:10, $\mathrm{w} / \mathrm{v}$ ) for $2 \mathrm{~h}$ at $20^{\circ} \mathrm{C}$ and then boiled twice for $30 \mathrm{~min}$ at $100^{\circ} \mathrm{C}$. The twice-boiled solutions were blended and filtered through a $0.2 \mu \mathrm{m}$ syringe filter (EMD Millipore). Finally, the filtered liquids were concentrated under pressure at $60^{\circ} \mathrm{C}$ and stored at $4^{\circ} \mathrm{C}$. tauroursodeoxycholic acid (TUDCA) is a water-soluble bile acid that is commonly used in clinical settings (30) and was provided by Bruschettini S.R.L. TUDCA was used as the positive control drug in the present study.

Animals and treatments. A total of 100 male specificpathogen-free grade C57BL/6 mice (age, 8 weeks; weight, $22.5 \pm 2.5 \mathrm{~g}$ ) were purchased from The Shanghai Model Organisms Center, Inc. All animals were housed in a controlled environment with the temperature at $22 \pm 1^{\circ} \mathrm{C}$, relative humidity of $60 \pm 10 \%$ and a 12-h light/dark cycle. Mice had free access to food and water throughout experimentation. All animal studies, including the mice euthanasia procedure, were approved and performed in compliance with the regulations and guidelines of the Ethics Committee of Shanghai University of Traditional Chinese Medicine and conducted according to the Association for Assessment and Accreditation of Laboratory Animal Care and the institutional animal care and use committee guidelines (approval no. PZSHUTCM191108007) (31,32).

After 1 week of acclimatization, mice were randomly divided into five groups ( $n=20$ mice per group; Fig. 1): i) Normal (N); ii) model (M); iii) low dose YCHD (YCHD-L); iv) high dose YCHD (YCHD-H); and v) positive control (TUDCA). Throughout the experiment, mice in the normal group were fed with standard mice chow, whilst all other mice were fed on a lithogenic diet, which consists of standard chow diet containing $1.25 \%$ cholesterol and $0.5 \%$ cholic acid (33). In addition, mice in the normal and model groups were provided with distilled water via oral gavage once a day from weeks 5 to 12 . Mice in the YCHD-L group were given a daily dose of $7 \mathrm{~g} / \mathrm{kg}$ body weight YCHD, whilst those in the YCHD-H group were given a daily dose of $14 \mathrm{~g} / \mathrm{kg}$ body weight YCHD. All YCHD treatments were administered once a day, for 8 consecutive weeks from weeks 5 to 12 . Mice in the TUDCA group were given a daily dose of $100 \mathrm{mg} / \mathrm{kg}$ TUDCA via oral gavage once a day for 8 consecutive weeks from weeks 5 to 12 . The amount of the TUDCA drug is equivalent to the clinical dose of $60 \mathrm{~kg} /$ day body weight in adults (34).

Animal health and behavior were monitored every day. In total, 10 mice in each group were randomly sacrificed at the end of week 8 , whilst the rest of the mice were sacrificed at the end of week 12. The humane endpoints established in the present study for animal euthanasia are as follows: i) Lack of responsiveness to manual stimulation; ii) immobility; and/or iii) an inability to eat or drink freely. Mice were anesthetized with $1 \%$ pentobarbital sodium $(40 \mathrm{mg} / \mathrm{kg})$ by intraperitoneal injection prior to exsanguination from the retroorbital vein. Mice were sacrificed with $150 \mathrm{mg} / \mathrm{kg}$ pentobarbital sodium by intraperitoneal injection. $100 \mu \mathrm{l}$ serum, as well as liver, gallbladder and intestine tissue samples, were then collected and stored at $-80^{\circ} \mathrm{C}$ for subsequent analysis. 


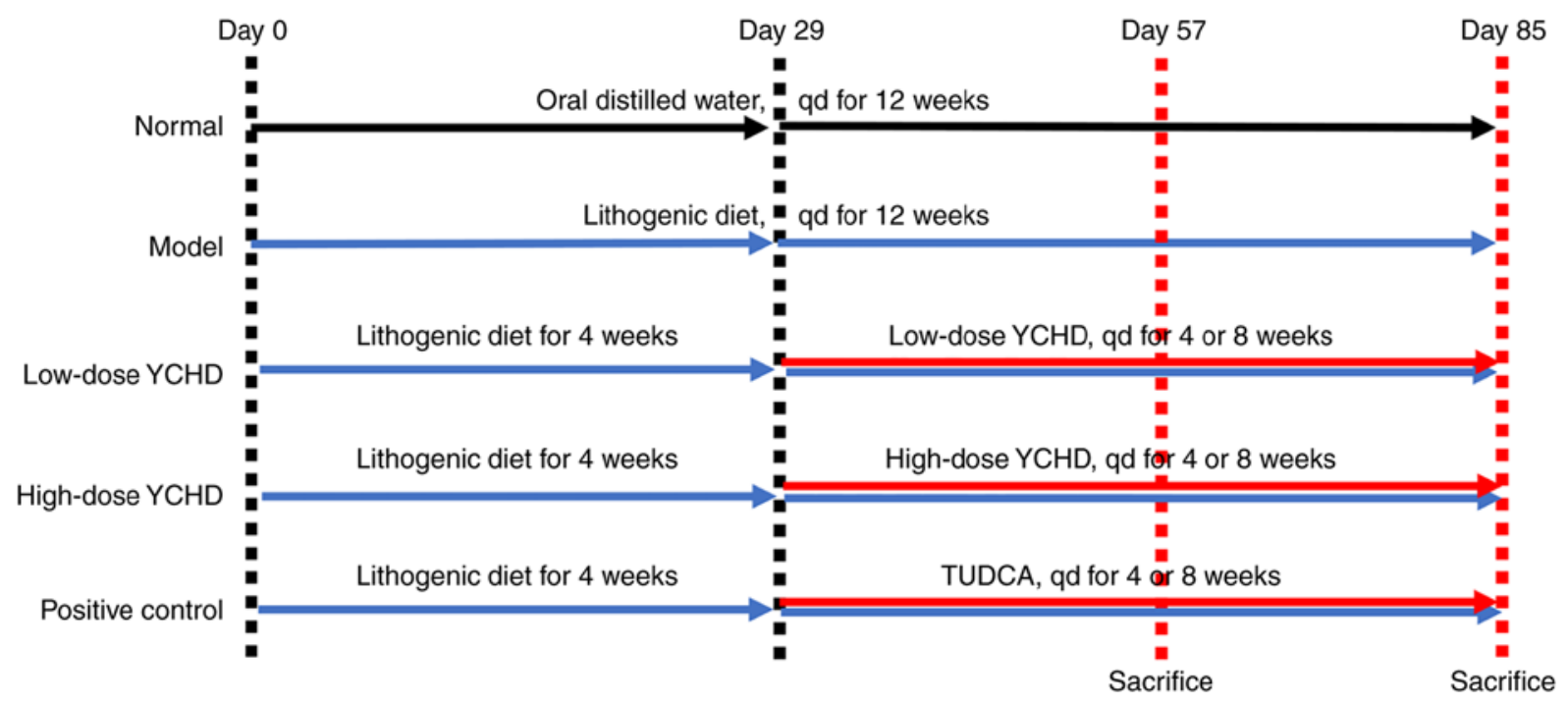

Figure 1. Scheme of the present study. Oral, oral administration; qd, quaque die; YCHD, Yinchenhao Decoction; TUDCA, tauroursodeoxycholic acid.

Biochemical assays. Serum was obtained by centrifuging the blood at $3,000 \mathrm{x} g$ for $15 \mathrm{~min}$ at $4^{\circ} \mathrm{C}$. The kits used for the determination of serum alanine aminotransferase (ALT; cat. no. HC41T02) and alkaline phosphatase (ALP) activities (cat. no. HC02T03), in addition to the levels of total cholesterol (TC; cat. no. HC12S03) and low-density lipoprotein cholesterol (LDL-C; cat. no. HC73T03) were purchased from Shanghai Huachen biological reagent Co. Ltd. Serum ALT and ALP activities and the levels of TC and LDL-C were measured using a TBA-40FR Biochemical Analyzer (Toshiba Corporation) according to the manufacturer's experimental protocol.

Analysis of cholelithiasis and bile. The presence of cholesterol crystals or stones in the bile was clearly visible to the naked eye and was graded according to the six-level judgment criteria previously described by Akiyoshi et al (35) in a double-blinded manner at the end of week 8 and 12. These criteria were as follows: i) Grade 0, gallbladder is filled with clear bile; ii) grade I, a few fine crystals are found; iii) grade II, $\sim 10$ fine crystals are found; iv) grade III: Fine crystals occupy $\sim 50 \%$ of the gallbladder; v) grade IV, crystals occupy $>50 \%$ of the gallbladder; and vi) grade $\mathrm{V}$, round gallstones are found. Bile was collected through common bile duct drainage. The levels of TC, phospholipids (PL) and total bile acid (TBA) in the bile were measured by enzyme colorimetry according to the manufacturer's experimental protocol, which were then used to calculate the cholesterol saturation index [CSI, moles percent (TC) x 100/(TC+PL+TBA)] (36). The TC detection kit was purchased from Roche Diagnostics (cat. no. 11491458216), the PL kit was from Wako Pure Chemical Industries Ltd. (cat. no. 296-63801) and the TBA kit was obtained from Randox Laboratories, Ltd. (cat. no. BI2672). All kits were used in accordance with the manufacturer's protocol.

Histopathological analysis. Liver tissues were fixed in $10 \%$ formalin for $24 \mathrm{~h}$ at room temperature, dehydrated in an ascending ethanol gradient, embedded in paraffin and cut into 5- $\mu \mathrm{m}$-thick sections. The sections were then stained with hematoxylin and eosin (H\&E, hematoxylin for $5 \mathrm{~min}$ and eosin for $20 \mathrm{sec}$ at room temperature) and observed under a light microscope (IX70; Olympus Corporation; magnification, $\mathrm{x} 100)$.

Reverse transcription-quantitative PCR (RT-qPCR). Total RNA was extracted from the liver and proximal small intestine tissues using TRIzol ${ }^{\boxplus}$ reagent according to manufacturer's protocol (Invitrogen; Thermo Fisher Scientific, Inc.). RNA concentration was determined by measuring the absorbance at wavelengths of 260 and $280 \mathrm{~nm}$ using the Nanodrop ${ }^{\mathrm{TM}} 2000$ ultra microspectrophotometer (Thermo Fisher Scientific, Inc.). High Capacity cDNA Reverse Transcription Kit (cat. no. 4368814; Thermo Fisher Scientific, Inc.) was used for reverse transcribing total RNA into cDNA, according to the manufacturer's protocol. Relative mRNA expression was then measured in triplicate in the QuantStudio ${ }^{\mathrm{TM}} 6$ Flex Real-time PCR Instrument, using PowerUp ${ }^{\mathrm{TM}} \mathrm{SYBR}^{\mathrm{TM}}$ Green Master Mix kit (cat. no. A25742; Thermo Fisher Scientific Inc.). The thermocycling conditions for the PCR assay cycles were as follows: Initial denaturation at $95^{\circ} \mathrm{C}$ for $1 \mathrm{~min}$, followed by 45 cycles of $95^{\circ} \mathrm{C}$ for $15 \mathrm{sec}$ and $60^{\circ} \mathrm{C}$ for $1 \mathrm{~min}$. GAPDH was used as the normalizing control gene, where the mRNA levels of target genes were measured using the $2^{-\Delta \Delta \mathrm{Cq}}$ method (37). The forward and reverse primer sequences that were used in the present study are shown in Table I.

Statistical analysis. All quantitative data were presented as the mean \pm SD and analyzed using the SPSS software (version 22.0; SPSS, Inc.). One-way ANOVA was used to analyze the differences between the groups, followed by Tukey's test. Grade data were analyzed using the Kruskal-Wallis test. $\mathrm{P}<0.05$ was considered to indicate a statistically significant difference.

\section{Results}

Effect of YCHD on the general parameters of mice. Throughout the experiment, the vitality and stools of mice were basically normal in appearance. Following prolonged feeding time of 
Table I. PCR primer sequences.

\begin{tabular}{lll}
\hline Gene & Primers & \multicolumn{1}{c}{ Sequence (5'-3') } \\
\hline GAPDH & Forward & TGTGTCCGTCGTGGATCTGA \\
& Reverse & CCTGCTTCACCACCTTCTTGAT \\
ABCG5 & Forward & AATGCTGTGAATCTGTTTCCCA \\
& Reverse & CCACTTATGATACAGGCCATCCT \\
ABCG8 & Forward & CTGTGGAATGGGACTGTACTTC \\
& Reverse & GTTGGACTGACCACTGTAGGT \\
SRBI & Forward & CGGGAGCGTGGACCCTATGT \\
& Reverse & ACACGGTGTCGTTGTCATTGA \\
ABCB11 & Forward & CAATAGACAGGCAACCCGTCA \\
& Reverse & GTGGAACTCAATTCGCCCTT \\
ABCB4 & Forward & GCAGCGAGAAACGGAACAG \\
& Reverse & GGTTGCTGATGCTGCCTAGTT \\
NP1CL1 & Forward & ATCCTCATCCTGGGCTTTGC \\
& Reverse & GCAAGGTGATCAGGAGGTTGA
\end{tabular}

ABCG5, ATP-binding cassette subfamily G member 5; ABCG8, ATP-binding cassette subfamily G member 8; SRBI, scavenger receptor class B type I; ABCB11, ATP-binding cassette subfamily B member 11; ABCB4, ATP-binding cassette subfamily B member 4; NPC1L1, Niemann-Pick C1 Like 1.

LD, the body weights of mice in the model group were significantly decreased compared with those in the normal group, whilst the liver weights and liver /body weight ratio of were also significantly increased $(\mathrm{P}<0.01$; Table II). Compared with those in the model group, mice in the YCHD-treated groups exhibited significantly reduced the liver weights $(\mathrm{P}<0.01)$ and liver/body weight ratios $(\mathrm{P}<0.05$; Table II), where high dose YCHD for 8 weeks demonstrated greater potency. Although treatment with TUDCA significantly reduced the liver weights and liver/body weight ratios in mice compared with those in the model group $(\mathrm{P}<0.01)$, no significant difference between the model and TUDCA groups was observed in body weight.

In comparison with those in the normal group, the serum levels of ALT, ALP, TC and LDL-C were found to be significantly increased in the model group $(\mathrm{P}<0.01)$ but reversed by YCHD treatment. When compared with the model group, low dose YCHD only significantly restored the serum level of ALT after treatment for 8 weeks $(\mathrm{P}<0.01)$, whereas high dose YCHD significantly restored the serum levels of ALT, ALP, TC and LDL-C in mice $(\mathrm{P}<0.01)$. Treatment with TUDCA also decreased the serum ALT, ALP, TC and LDL-C levels compared with the model group $(\mathrm{P}<0.01)$ and those in the YCHD-L group $(\mathrm{P}<0.05$; Table II).

Effect of YCHD on cholelithiasis in mice. The estimated extent of cholelithiasis in mice was visually graded according to the six-level judgment criteria (Fig. 2). Compared with that in the normal group, there was a statistically significant increased difference in the grade of gallstones in the model group $(\mathrm{P}<0.01)$. LD-fed C57BL/6 mice exhibited a $100 \%$ cholelithiasis formation rate, where the severity of cholelithiasis was directly associated with feeding time. There was also a decreased tendency of cholelithiasis formation for each treatment group in comparison to the model group (Fig. 2).

Effect of YCHD on biliary lipid composition and CSI in mice. The biliary lipid composition and CSI of mice in the five treatment groups are shown in Fig. 3. For feeding LD at 8 weeks, the concentration of TC in the model group was significantly increased $(\mathrm{P}<0.01)$ compared with the normal group, while the TBA content was decreased $(\mathrm{P}<0.05)$. Feeding LD for 12 weeks resulted in significantly increased concentrations of TC and PL in the model group $(\mathrm{P}<0.01)$ compared with the normal group. Additionally, TBA content was significantly decreased $(\mathrm{P}<0.05)$. In addition, the severity of CSI in the model group was also found to be significantly increased compared with that in the control group $(\mathrm{P}<0.01)$, suggesting that the levels of cholesterol in the bile was supersaturated and the relative dynamic balance between TC, PL and TBA was disrupted. After treatment with high dose YCHD for 4 weeks, the concentration of TC and CSI in bile was reduced $(\mathrm{P}<0.05)$, whilst TBA content was increased $(\mathrm{P}<0.05)$ compared with the model group. After treatment with YCHD-L or YCHD-H for 8 weeks, the concentration of TC, PL and CSI in the bile was significantly reduced $(\mathrm{P}<0.01)$, whilst $\mathrm{TBA}$ content was significantly increased $(\mathrm{P}<0.01)$ compared with the model group, indicating that YCHD restored the imbalance in the bile, thereby ameliorating cholelithiasis in mice. The difference between the high dose and low dose groups at 8 -weeks of treatment was also found to be significant $(\mathrm{P}<0.05)$. The same results were found for the TUDCA group compared with the model group $(\mathrm{P}<0.01)$ and the YCHD-L group $(\mathrm{P}<0.05)$.

Histopathological effect of YCHD in mice. As shown in Fig. 4, with prolonged feeding on LD, TC levels in the liver tissue of the model group were revealed to be significantly increased compared with those in the normal group $(\mathrm{P}<0.01)$. Compared with the model group, TC levels in the liver tissue of the YCHD-H group were significantly reduced $(\mathrm{P}<0.01)$. The potency of high dose treatment for 8 weeks was significantly higher compared with the low dose group $(\mathrm{P}<0.01)$. Treatment with TUDCA also significantly reduced hepatic TC levels compared with those in the model group $(\mathrm{P}<0.01)$ and the YCHD-L group $(\mathrm{P}<0.01)$.

Representative images of liver specimens stained with $H \& E$ are shown in Fig. 5. H\&E staining showed that all the mice in the normal group appeared to have normal structures. However, the cytoplasm of hepatocytes isolated from mice in the model group was loose, along with inflammatory cell infiltration and capillary bile duct hyperplasia. In addition, the degree of hepatocyte injury was positively associated the length of the modeling time. Local capillary bile duct hyperplasia occurred in the mice fed on LD for 8 weeks, whilst capillary bile duct hyperplasia in the liver parenchyma was evident in mice fed on LD for 12 weeks. In the YCHD-treated groups, the extents of cytoplasmic loosening in hepatocytes, inflammatory cell infiltration and damage to hepatocytes were all alleviated with the preferable changes observed in the high dose group. These findings suggest that YCHD treatment reduced cholesterol deposition in liver tissues and attenuated the pathological changes of hepatocyte injury. 
Table II. Biochemical parameters of serum and liver.

A, After treatment for 4 weeks

\begin{tabular}{lccccc}
\hline Parameters & $\mathrm{N}$ & $\mathrm{M}$ & YCHD-L & YCHD-H & TUDCA \\
\hline Number of mice & 10 & 10 & 9 & 10 & 10 \\
Body weight (g) & $27.85 \pm 3.31$ & $24.65 \pm 1.92^{\mathrm{a}}$ & $24.05 \pm 1.15$ & $24.09 \pm 1.19$ & $23.53 \pm 1.29$ \\
Liver weight (g) & $1.13 \pm 0.16$ & $1.99 \pm 0.23^{\mathrm{a}}$ & $2.02 \pm 0.18$ & $1.79 \pm 0.12$ & $1.46 \pm 0.28^{\mathrm{c}, \mathrm{e}}$ \\
Liver/body weight ratio (\%) & $4.06 \pm 0.32$ & $8.07 \pm 0.45^{\mathrm{a}}$ & $8.4 \pm 0.61$ & $7.47 \pm 0.61^{\mathrm{d}}$ & $6.18 \pm 0.94^{\mathrm{c}, \mathrm{e}}$ \\
ALT (U/l) & $40.57 \pm 14.21$ & $412.45 \pm 176.27^{\mathrm{a}}$ & $355.43 \pm 77.11$ & $201.44 \pm 78.72^{\mathrm{c}}$ & $98.3 \pm 68.59^{\mathrm{c}, \mathrm{d}}$ \\
ALP (U/l) & $51.71 \pm 12.45$ & $220.4 \pm 73.43^{\mathrm{a}}$ & $201.14 \pm 65.03$ & $159.38 \pm 40.65$ & $124.4 \pm 49.99^{\mathrm{c}}$ \\
TC (mmol/l) & $2.5 \pm 0.62$ & $5.12 \pm 1.25^{\mathrm{a}}$ & $5.43 \pm 0.7$ & $4.69 \pm 1.19$ & $3.74 \pm 1.61$ \\
LDL-C (mmol/l) & $0.23 \pm 0.07$ & $0.98 \pm 0.29^{\mathrm{a}}$ & $0.94 \pm 0.06$ & $0.9 \pm 0.24$ & $0.74 \pm 0.34$ \\
\hline
\end{tabular}

B, After treatment for 8 weeks

\begin{tabular}{lccccc}
\hline Parameters & $\mathrm{N}$ & $\mathrm{M}$ & YCHD-L & YCHD-H & TUDCA \\
\hline Number of mice & 10 & 9 & 9 & 10 & 10 \\
Body weight (g) & $32.69 \pm 3.29$ & $22.81 \pm 1.92^{\mathrm{a}}$ & $22.38 \pm 2.24$ & $23.06 \pm 2.4$ & $23.42 \pm 1.18$ \\
Liver weight (g) & $1.21 \pm 0.13$ & $2.83 \pm 0.37^{\mathrm{a}}$ & $2.4 \pm 0.35^{\mathrm{b}}$ & $2.2 \pm 0.24^{\mathrm{c}}$ & $1.45 \pm 0.27^{\mathrm{c}, \mathrm{e}}$ \\
Liver/body weight ratio (\%) & $3.69 \pm 0.15$ & $12.4 \pm 1.22^{\mathrm{a}}$ & $10.86 \pm 2.26$ & $9.57 \pm 0.86^{\mathrm{c}}$ & $6.18 \pm 0.85^{\mathrm{c}, \mathrm{e}}$ \\
ALT (U/l) & $46.29 \pm 5.31$ & $595.63 \pm 234.26^{\mathrm{a}}$ & $350.22 \pm 84.47^{\mathrm{c}}$ & $289.14 \pm 71.99^{\mathrm{c}}$ & $76.6 \pm 89.45^{\mathrm{c}, \mathrm{e}}$ \\
ALP (U/l) & $63.57 \pm 11.36$ & $333.38 \pm 68.32^{\mathrm{a}}$ & $247.56 \pm 99.45$ & $170.43 \pm 52.28^{\mathrm{c}}$ & $132.5 \pm 50.32^{\mathrm{c}, \mathrm{e}}$ \\
TC (mmol/l) & $1.92 \pm 0.61$ & $5.76 \pm 0.86^{\mathrm{a}}$ & $4.36 \pm 1$ & $3.72 \pm 1.68^{\mathrm{c}}$ & $2.76 \pm 0.91^{\mathrm{c}, \mathrm{d}}$ \\
LDL-C (mmol/l) & $0.17 \pm 0.03$ & $1.03 \pm 0.27^{\mathrm{a}}$ & $0.81 \pm 0.28$ & $0.66 \pm 0.29^{\mathrm{b}}$ & $0.49 \pm 0.23^{\mathrm{c}}$
\end{tabular}

${ }^{\mathrm{a}} \mathrm{P}<0.01$ vs. $\mathrm{N}$; ${ }^{\mathrm{b}} \mathrm{P}<0.05,{ }^{\mathrm{C}} \mathrm{P}<0.01$ vs. $\mathrm{M}$; ${ }^{\mathrm{d}} \mathrm{P}<0.05,{ }^{\mathrm{e}} \mathrm{P}<0.01$ vs. YCHD-L. N, normal; M, model; L, low dose; H, high dose; YCHD, Yinchenhao Decoction; TUDCA, tauroursodeoxycholic acid; ALT, alanine aminotransferase; ALP, alkaline phosphatase; TC, total cholesterol; LDL-C, low-density lipoprotein cholesterol.

Effect of YCHD on the expression of key components of cholesterol metabolisms in the liver and small intestine tissues of mice. As shown in Fig. 6, compared with those in the normal group, the expression levels of liver ABCG5, ABCG8, SRBI and ABCB11 mRNA in the 8-weeks model group were significantly increased $(\mathrm{P}<0.01)$. Additionally, the expression levels of liver ABCG5, ABCG8 and SRBI mRNA in the 12-week model group were significantly increased $(\mathrm{P}<0.01)$. In addition, the relative expression of ABCG5, ABCG8 and NPC1L1 in the proximal small intestine were also significantly increased compared with that in the normal group $(\mathrm{P}<0.01)$. After treatment with YCHD for 4 weeks, compared with those in the model group, the aforementioned increased expression of ABCG5, ABCG8, SRBI, ABCB11 and ABCB4 in the liver and ABCG5, ABCG8 and NPC1L1 in the small intestine were all significantly reversed in the YCHD-L $(\mathrm{P}<0.01)$ and YCHD-H $(\mathrm{P}<0.01)$ groups. Similar to YCHD, treatment with TUDCA also significantly reversed the increased ABCG5, ABCG8, NPC1L1 and SRBI expression in the liver and/or small intestine compared with those in the model group $(\mathrm{P}<0.01)$.

\section{Discussion}

Gallstone disease is highly prevalent among the general population, with incidence ranging from 10-15\% in Europe, the USA and other developed countries (38). The majority of symptomatic gallstone diseases are caused by cholesterol gallstones (39). From a therapeutic point of view, effective treatment options for cholesterol gallstones are limited and the cost of therapeutic interventions are high. Surgery can result in potential side effects, whilst oral litholysis with hydrophilic bile salts has demonstrated limited effectiveness (40). Therefore, it remains necessary to explore promising novel agents to confront the problem of this increasing prevalence of cholelithiasis to aid the progress of therapeutic and drug development.

The etiology of gallstone formation is multifactorial, which includes gender, genetic, lifestyle and comorbidity-associated factors (41). Cholesterol gallstones tend to occur more frequently in women compared with men due to elevated estrogen levels (42). The pathogenesis of gallstone includes hepatic hypersecretion of cholesterol, supersaturated bile and rapid phase transition of cholesterol, gallbladder hypomotility and intestinal factors $(43,44)$. A previous study has shown that excessive intake of cholesterol leads to increased cholesterol levels in the blood and increased cholesterol saturation in the bile in the human body, eventually leading to the formation of gallstones (45). In the present study, LD was used to induce cholelithiasis in male mice. Since the role of estrogen in regulating cholesterol and bile acid metabolism in the liver has 
A

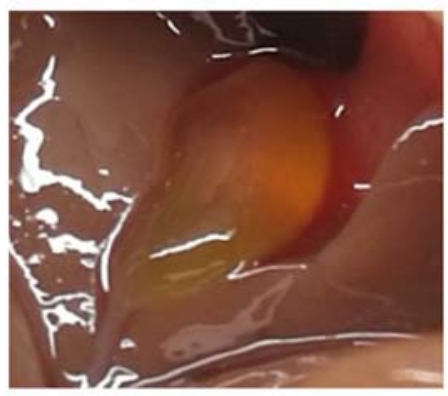

Grade 0

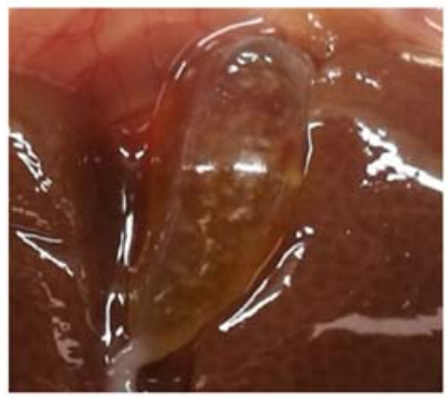

Grade III

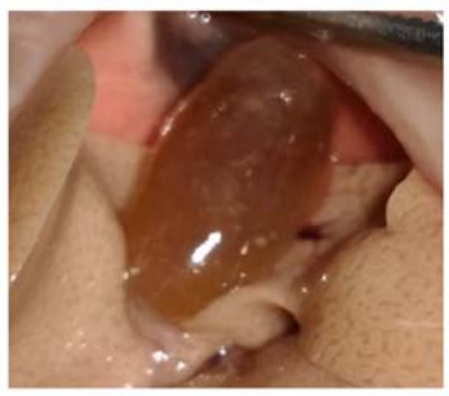

Grade I

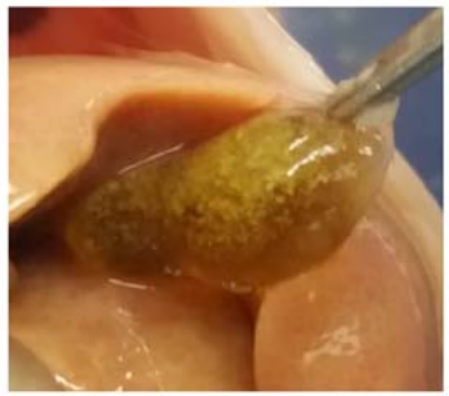

Grade IV

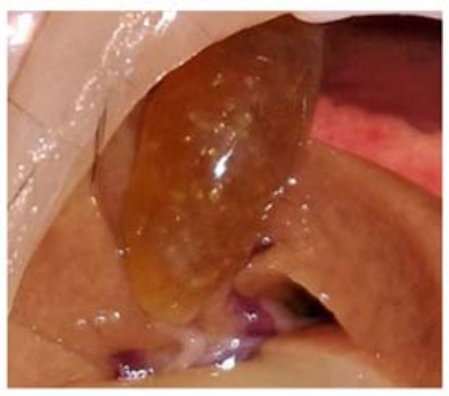

Grade II

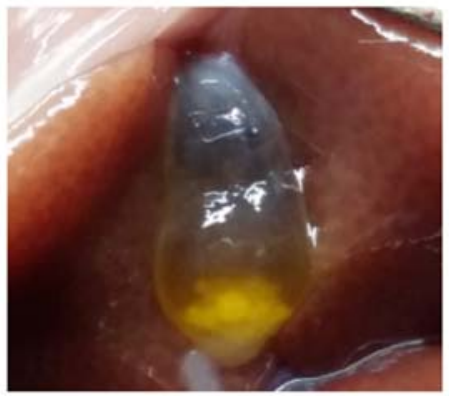

Grade V
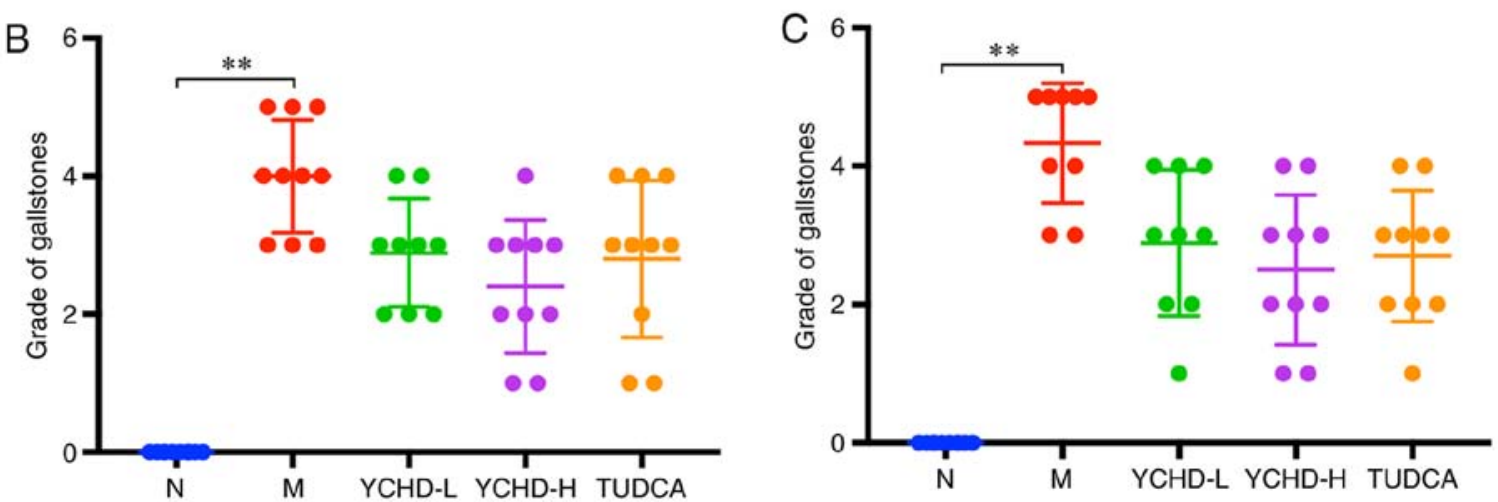

Figure 2. Conditions of mice with cholelithiasis in the five different groups. (A) Representative images of gallbladders with each category of cholelithiasis, as graded using the six-level judgment criteria: Grade 0, gallbladder is filled with clear bile; grade I: A few fine crystals are found; grade II, $\sim 10$ fine crystals are found; grade III, fine crystals occupy $\sim 50 \%$ of the gallbladder; grade IV: Crystals occupy $>50 \%$ of the gallbladder; grade V: Round gallstones are found. The grade of cholelithiasis in mice after (B) treatment for 4 weeks (C) and for 8 weeks. ${ }^{* *} \mathrm{P}<0.01$. N, normal; M, model; L, low dose; H, high dose; YCHD, Yinchenhao Decoction; TUDCA, tauroursodeoxycholic acid.

been demonstrated in a previous study (46), male mice were used to rule out the impact of estrogen on the present study of drug efficacy. The results showed that compared with the that in the normal group, cholelithiasis model was successfully established in LD-fed C57BL/6 mice. The presence of cholesterol crystals or stones was clearly visible in the gallbladder of these mice, where the severity of cholelithiasis was positively associated with the modeling time. Treatment with YCHD or TUDCA improved the condition of cholelithiasis in mice. Based on these findings, the mechanism of YCHD-mediated cholelithiasis formation inhibition was further examined by measuring biochemical indices in the serum in addition to analyzing liver tissue pathology, gallbladder bile composition and expression levels of proteins involved in cholesterol metabolism.

Positive associations between high serum lipid levels, liver enzymes and the development of cholesterol gallstones, have been previously reported (47). Compared with healthy individuals, patients with gallstones showed higher TC and LDL-C levels (48). High serum cholesterol and LDL levels may increase cholesterol excretion with bile and cause cholesterol gallstone disease $(49,50)$. In liver enzyme profiles, patients with gallstones presented with higher serum ALT and ALP activities (51). The results of the present study were consistent with previous reports, where levels of serum ALT, ALP, TC and LDL-C levels in the mice in the model group were significantly increased compared with those in the normal group, reflective of hepatic injury and the pathological status. It has been previously documented that hepatic cholesterol accumulation causes pathological liver damage and inflammation (52). In the present study, TC levels in the liver tissues of mice in the model group were also found to be significantly increased. H\&E staining of liver tissues showed that the cytoplasm of hepatocytes in mice in the model group was loose with inflammatory cell infiltration and capillary bile duct hyperplasia. In addition, the degree of hepatocyte injury was associated with modeling time. These pathological results were consistent with the results of serum biochemical indicators, confirming that there was hepatocyte injury in mice 

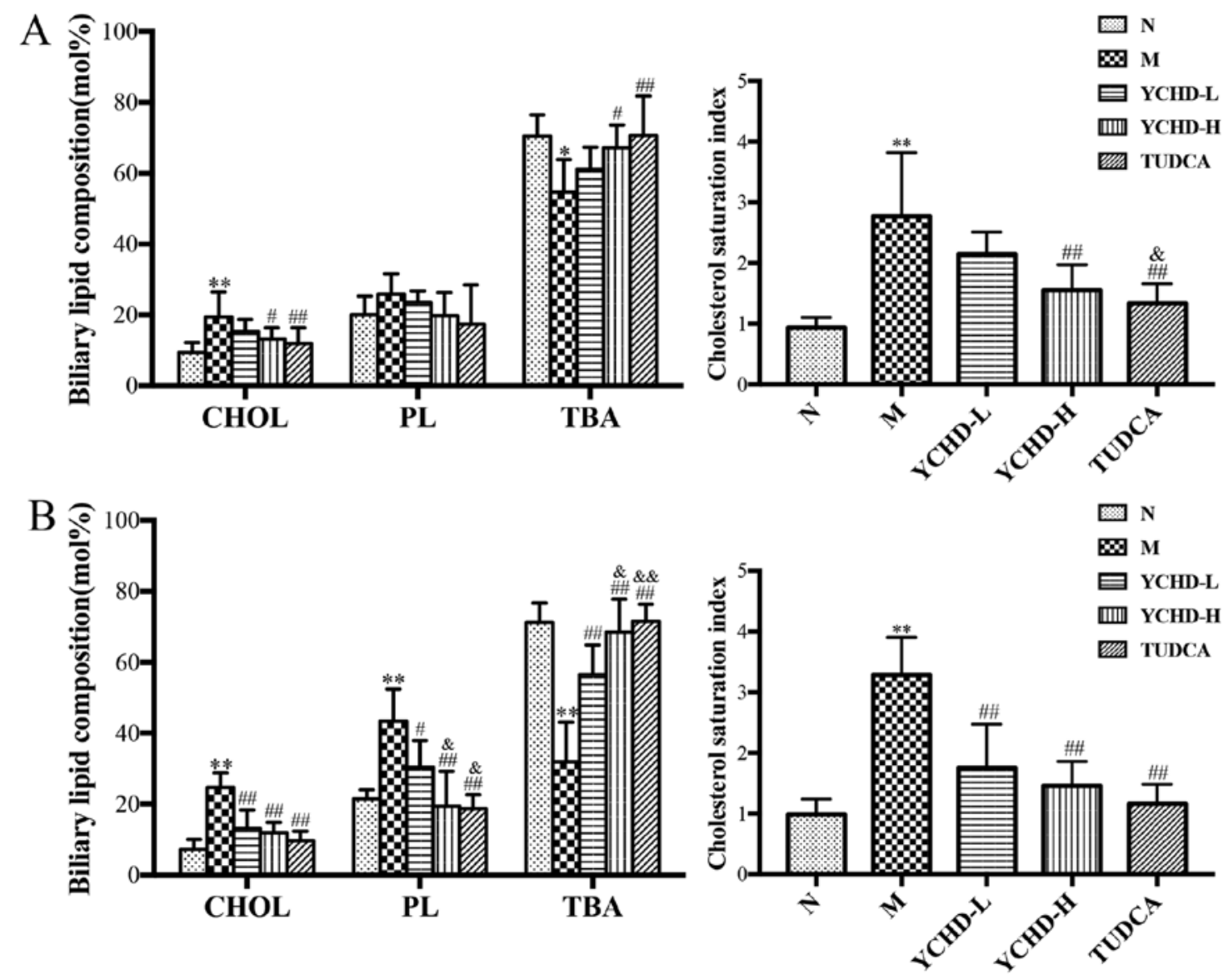

Figure 3. Biliary lipid composition and cholesterol saturation index in mice from the five treatment groups. Measurements of cholesterol, phospholipids and total bile acid after treatment for (A) 4 weeks and (B) 8 weeks. ${ }^{*} \mathrm{P}<0.05$, ${ }^{* *} \mathrm{P}<0.01$ vs. $\mathrm{N} ;{ }^{\#} \mathrm{P}<0.05$, ${ }^{\# \#} \mathrm{P}<0.01 \mathrm{vs.} \mathrm{M}$; ${ }^{\&} \mathrm{P}<0.05$, \&\& $\mathrm{P}<0.01$ vs. YCHD-L. N, normal; M, model; L, low dose; H, high dose; YCHD, Yinchenhao Decoction; TUDCA, tauroursodeoxycholic acid; TC, total cholesterol; PL, phospholipid; TBA, total bile acid.
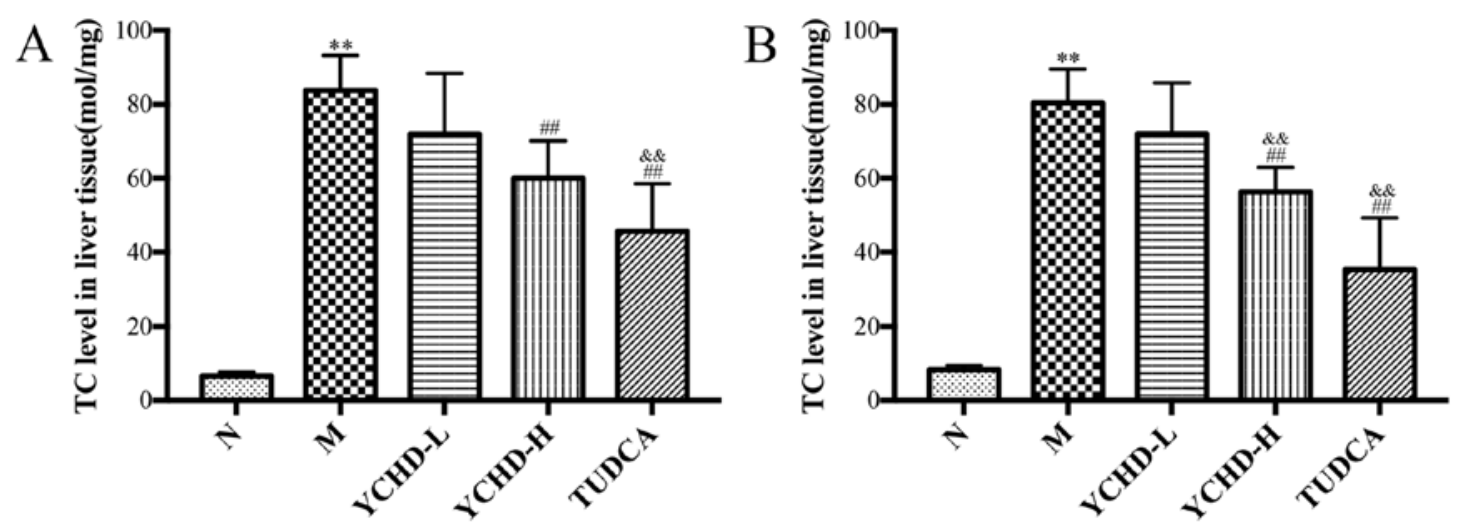

Figure 4. Total cholesterol levels in liver tissues isolated from mice from the five treatment groups. Measurements of cholesterol after treatment (A) for 4 weeks and (B) 8 weeks. ${ }^{* *} \mathrm{P}<0.01$ vs. N. ${ }^{\# \#} \mathrm{P}<0.01$ vs. M; ${ }^{\&} \mathrm{P}<0.01$ vs. YCHD-L. N, normal; M, model; L, low dose; H, high dose; YCHD, Yinchenhao Decoction; TUDCA, tauroursodeoxycholic acid; TC, total cholesterol.

in the model group. The intervention of YCHD or TUDCA significantly reversed the increased serum lipid and liver injury indicator levels and alleviated the damage to the hepatocytes. The extent of restoration of damaged hepatocytes was found to be proportional to the dose of treatment of YCHD. These results are in line with earlier reports, which demonstrated that YCHD treatment could repair liver injury and reverse steatosis $(53,54)$.

Lithogenicity of the bile is determined by the relative concentration of cholesterol, phospholipids and bile acids that are synthesized in the hepatocytes (55). Cholesterol and phospholipids are insoluble in water and must be combined with bile acids to form mixed micelles under normal circumstances (56). When cholesterol is excessively secreted or the excretion of bile salts or phospholipids are reduced, impaired lipid absorption leads to the sustained supersaturation of cholesterol, increasing the susceptibility to cholesterol crystallization and gallstone formation $(57,58)$. Cholesterol supersaturation or deficiency of bile acids in the bile results 

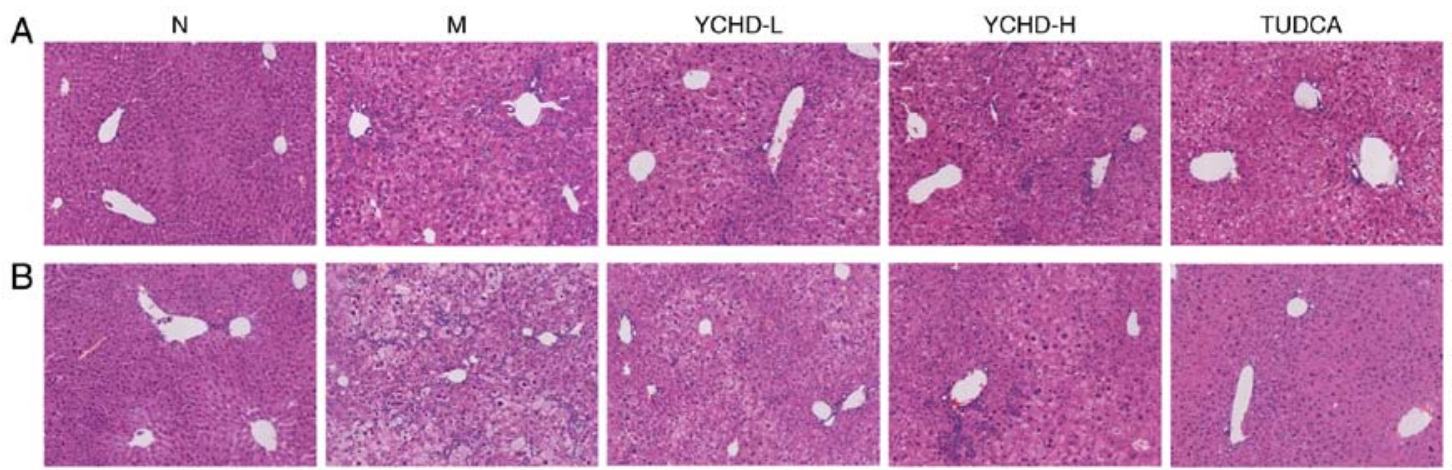

Figure 5. Hematoxylin and eosin staining of liver sections from mice from the five treatment groups. Representative histopathological images of mice from the five groups after treatment for (A) 4 weeks and (B) 8 weeks. Magnification, x100. N, normal; M, model; L, low dose; H, high dose; YCHD, Yinchenhao Decoction; TUDCA, tauroursodeoxycholic acid.
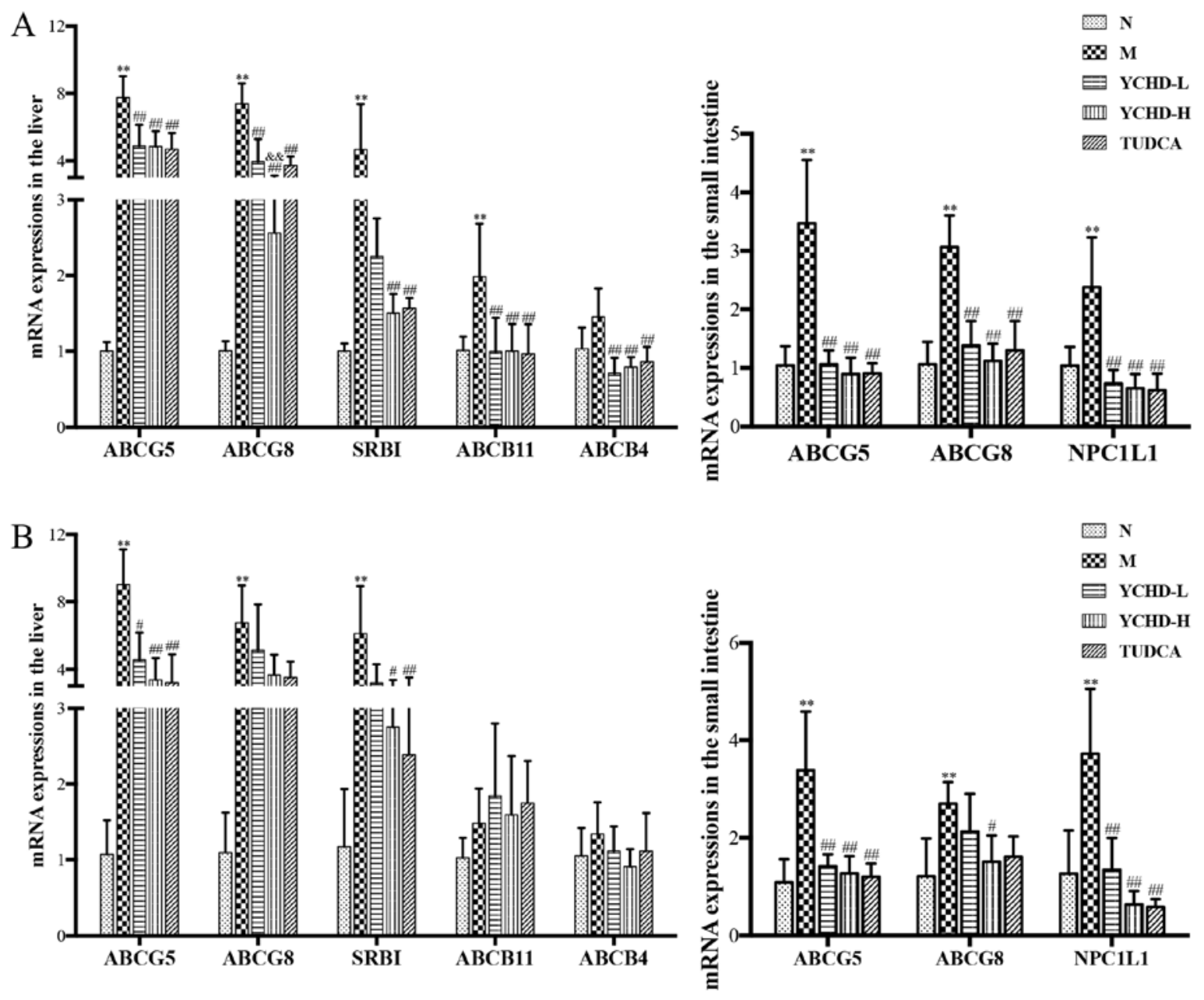

Figure 6. Expression of key components of the cholesterol metabolism pathway in the liver and small intestine tissues of mice from the five treatment groups. Measurements of ABCG5, ABCG8, NPC1L1, SRBI, ABCB11 and ABCB4 mRNA expression in liver and small intestine tissues of mice from the five treatment groups after treatment for (A) 4 weeks and (B) 8 weeks. ${ }^{* *} \mathrm{P}<0.01$ vs. N; ${ }^{~} \mathrm{P}<0.05,{ }^{\# \#} \mathrm{P}<0.01$ vs. $\mathrm{M}$; ${ }^{\& \&} \mathrm{P}<0.01$ vs. YCHD-L. N, normal; M, model; L, low dose; H, high dose; YCHD, Yinchenhao Decoction; TUDCA, tauroursodeoxycholic acid; ABCG, ATP-binding cassette subfamily G; SRBI, scavenger receptor class B type I; ABCB, ATP-binding cassette subfamily B; NPC1L1, Niemann-Pick C1 Like 1.

in a high CSI value, which is a semi-quantitative measure of the biliary cholesterol content (59). A significantly higher CSI value was previously found in patients with cholelithiasis compared to that in healthy individuals (60). These observations are supported by the present study, where mice in the model group showed significantly increased biliary CHOL concentrations, higher CSI values and reduced TBA concentrations, suggesting failure of biliary cholesterol homeostasis. Treatment with YCHD or TUDCA reversed this alteration in biliary lipid and cholesterol contents and restored the dynamic imbalance, thereby inhibiting the formation and growth of cholesterol gallstones. 
Cholesterol is absorbed in the small intestine, transported in the blood and taken up by the liver (61). Hepatic secretion of bile salts and cholesterol into the bile forms the basis for eliminating excess cholesterol from the body (62). Cholesterol homeostasis in the body is mainly maintained by intestinal cholesterol absorption, cholesterol uptake and de novo biosynthesis in the liver, biliary excretion and its conversion to various products such as bile acids (63). ABCG5/G8 and SRBI are the principal mediators of biliary cholesterol efflux that prevent intestinal cholesterol absorption and facilitate cholesterol efflux from the liver $(42,43)$. This has the effect of simultaneously lower plasma cholesterol levels and increase biliary cholesterol excretion $(64,65)$. ABCB4 and ABCB11 transporter also have been reported to regulate the composition of primary bile $(66,67)$. The process of intestinal cholesterol absorption is a complex process, but it is clear that the small intestine serves a vital role in both dietary and biliary cholesterol absorption (68). Cholesterol uptake can also be regulated by variants of NPC1L1, a transmembrane protein that is highly expressed in the intestinal epithelial cells of the small intestine in mammals (69). Increased expression of these transporters has been previously demonstrated to increase biliary sterol secretion whilst reducing intestinal cholesterol absorption during cholelithiasis $(70,71)$. The relative expression levels of these critical components involved in lipid metabolism were measured in the present study to further clarify the mechanism of YCHD on cholelithiasis. YCHD effectively inhibited the overexpression of ABCG5/8 and SRBI transporters in the liver and ABCG5/8 and NPC1L1 in the small intestine, which promote cholesterol secretion back into the intestinal lumen. This potentially served to reduce intestinal cholesterol absorption and hepatic cholesterol transportation, in turn protecting against the formation and growth of cholesterol gallstones.

According to rules of TCM theory, classic formulae consist of the following four elements: i) The monarch drug, which is the core in this formula and directly targets the disease; ii) the minister drug, which promotes the therapeutic effect of the monarch drug or target the accompanying symptoms; iii) the assistant drug, which reduces the adverse effects and/or increase the potency of the whole formula; and iv) the servant drug, which guides the monarch and minister drugs to reach the target organs or to harmonize their actions (72). The therapeutic efficacy of YCHD can be attributed to the combined action of a mixture of the three herbs, Artemisiae scopariae herba, Gardeniae Fructus and Radix et Rhizoma Rhei. They harmoniously interacted with each other to achieve the therapeutic outcome and diminished the possible adverse reactions among the multiple herbs. Previous pharmacological studies indicated that synergism between three components tend to exert a more robust effect compared with either one or two of the three individual compounds, by hitting multiple targets (73).

YCHD has been previously used in clinical practice for jaundice and liver disorders. Previous studies have verified the efficacy and mechanism of YCHD for the treatment of diseases, including cholestatic liver disease, liver fibrosis and non-alcoholic steatohepatitis (74-76). However, insufficient studies have examined its effect and possible mechanism on cholelithiasis. The occurrence of cholelithiasis is closely associated with abnormal cholesterol metabolism, which involves the synthesis, absorption and transportation of cholesterol in the liver, gallbladder and intestine. The possible mechanism of YCHD was initially confirmed in vivo in mice with cholelithiasis based on the cholesterol metabolism pathway in the liver and intestine in the present study. The present study is a useful attempt on the study of this TCM formula for the treatment of cholelithiasis. For future studies, the specific mechanisms of YCHD on cholelithiasis from multiple perspectives will be further explored through additional in vitro and in vivo experiments, including its effects on inflammation and intestinal flora through metabolomics. In addition, the dose of YCHD used in the present study was the same or twice of the original prescription, which is far less than the maximum available dose (77). In future studies, a higher dose and a longer course of treatment will be applied.

In conclusion, the present study demonstrated that YCHD ameliorates serum and liver biochemical abnormalities in mice with LD-induced cholelithiasis and improves biliary cholesterol supersaturation to adjust biliary cholesterol homeostasis, which may involve the regulation of cholesterol metabolism.

\section{Acknowledgements}

Not applicable.

\section{Funding}

The present study was supported by the National Natural Science Foundation for Youth Scholars of China (grant no. 81603560), the Discipline Leader Program of Pudong New Area (grant no. PWRd2019-04), the Peak Discipline Project of Preventive Treatment of Disease in Traditional Chinese Medicine of Pudong New Area (grant no. PDZY-2018-0603) and Science and Technology Innovation Action Plan of Science and Technology Commission of Shanghai Municipality (grant no. 19401972700).

\section{Availability of data and materials}

The datasets used and/or analyzed during the current study are available from the corresponding author on reasonable request.

\section{Authors' contributions}

QZ performed the animal study, collected samples, acquired the data for analyses and drafted the manuscript. $\mathrm{HH}$ performed the animal study and analyzed the data. GZ acquired the data for analyses and analyzed the data. PL designed the study and revised the manuscript. YW designed the study and drafted the manuscript. HZ designed the study and revised the manuscript. All authors read and approved the final manuscript.

\section{Ethics approval and consent to participate}

The present study protocol was approved by the Animal Ethics Committee of Shanghai University of Traditional Chinese Medicine (Shanghai, China). 


\section{Patient consent for publication}

Not applicable.

\section{Competing interests}

The authors declare that they have no competing interests.

\section{References}

1. Stinton LM and Shaffer EA: Epidemiology of gallbladder disease: Cholelithiasis and cancer. Gut Liver 6: 172-187, 2012.

2. Zhu L, Aili A, Zhang C, Saiding A and Abudureyimu K Prevalence of and risk factors for gallstones in Uighur and Han Chinese. World J Gastroenterol 20: 14942-14949, 2014.

3. Littlefield A and Lenahan C: Cholelithiasis: Presentation and management. J Midwifery Womens Health 64: 289-297, 2019.

4. Reshetnyak VI: Concept of the pathogenesis and treatment of cholelithiasis. World J Hepatol 4: 18-34, 2012.

5. Cremer A and Arvanitakis M: Diagnosis and management of bile stone disease and its complications. Minerva Gastroenterol Dietol 62: 103-129, 2016.

6. Venneman NG and van Erpecum KJ: Pathogenesis of gallstones. Gastroenterol Clin North Am 39: 171-183, vii, 2010.

7. Dikkers A, Freak de Boer J, Annema W, Groen AK and Tietge UJ: Scavenger receptor BI and ABCG5/G8 differentially impact biliary sterol secretion and reverse cholesterol transport in mice. Hepatology 58: 293-303, 2013

8. Van Erpecum KJ: Pathogenesis of cholesterol and pigment gallstones: An update. Clin Res Hepatol Gastroenterol 35: 281-287, 2011.

9. Hoekstra $M$ and Sorci-Thomas M: Rediscovering scavenger receptor type BI: Surprising new roles for the HDL receptor. Curr Opin Lipidol 28: 255-260, 2017.

10. Chan J and Vandeberg JL: Hepatobiliary transport in health and disease. Clin Lipidol 7: 189-202, 2012.

11. Patel SB, Graf GA and Temel RE: ABCG5 and ABCG8: More than a defense against xenosterols. J Lipid Res 59: 1103-1113, 2018.

12. Krawczyk M, Lütjohann D, Schirin-Sokhan R, Villarroel L, Nervi F, Pimentel F, Lammert F and Miquel JF: Phytosterol and cholesterol precursor levels indicate increased cholesterol excretion and biosynthesis in gallstone disease. Hepatology 55: $1507-1517,2012$.

13. Reboul E, Soayfane Z, Goncalves A, Cantiello M, Bott R, Nauze M, Tercé F, Collet X and Coméra C: Respective contributions of intestinal Niemann-Pick C1-like 1 and scavenger receptor class B type I to cholesterol and tocopherol uptake: In vivo v. in vitro studies. Br J Nutr 107: 1296-1304, 2012.

14. Vinarova L, Vinarov Z, Tcholakova S, Denkov ND, Stoyanov S and Lips A: The mechanism of lowering cholesterol absorption by calcium studied by using an in vitro digestion model. Food Funct 7: 151-163, 2016.

15. Portincasa P, Ciaula AD, Bonfrate L and Wang DQ: Therapy of gallstone disease: What it was, what it is, what it will be. World J Gastrointest Pharmacol Ther 3: 7-20, 2012.

16. European Association for the Study of the Liver. Electronic address: easloffice@easloffice.eu: EASL Clinical Practice Guidelines on the prevention, diagnosis and treatment of gallstones. J Hepatol 65: 146-181, 2016.

17. Chen Q, Zhang Y, Li S, Chen S, Lin X, Li C and Asakawa T: Mechanisms underlying the prevention and treatment of cholelithiasis using traditional chinese medicine. Evid Based Complement Alternat Med 2019: 2536452, 2019.

18. Zhang A, Sun H, Yuan Y, Sun W, Jiao G and Wang X: An in vivo analysis of the therapeutic and synergistic properties of Chinese medicinal formula Yin-Chen-Hao-Tang based on its active constituents. Fitoterapia 82: 1160-1168, 2011.

19. Huang J, Cheung F, Tan HY, Hong M, Wang N, Yang J, Feng Y and Zheng Q: Identification of the active compounds and significant pathways of yinchenhao decoction based on network pharmacology. Mol Med Rep 16: 4583-4592, 2017.

20. Wang X, Zhang A, Wang P, Sun H, Wu G, Sun W, Lv H, Jiao G, $\mathrm{Xu} \mathrm{H}$, Yuan Y, et al: Metabolomics coupled with proteomics advancing drug discovery toward more agile development of targeted combination therapies. Mol Cell Proteomics 12: $1226-1238,2013$
21. Chen Z, Ma X, Zhao Y, Wang J, Zhang Y, Li J, Wang R, Zhu Y, Wang $L$ and Xiao $X$ : Yinchenhao decoction in the treatment of cholestasis: A systematic review and meta-analysis. J Ethnopharmacol 168: 208-216, 2015.

22. Li JY, Cao HY, Sun L, Sun RF, Wu C, Bian YQ, Dong S, Liu P, and Sun MY: Therapeutic mechanism of Yin-Chen-Hao decoction in hepatic diseases. World J Gastroenterol 23: 1125-1138, 2017.

23. Asakawa T, Yagi M, Tanaka Y, Asagiri K, Kobayashi H, Egami H, Tanikawa $\mathrm{K}$ and Kage M: The herbal medicine Inchinko-to reduces hepatic fibrosis in cholestatic rats. Pediatr Surg Int 28: 379-384, 2012.

24. Wang B, Sun MY, Long AH, Cao HY, Ren S, Bian YQ, Lu X, $\mathrm{Gu}$ HT, Liu CH and Liu P: Yin-Chen-Hao-Tang alleviates biliary obstructive cirrhosis in rats by inhibiting biliary epithelial cell proliferation and activation. Pharmacogn Mag 11: 417-425, 2015.

25. Man-ting L, Ying F, and Shao-Dong C: Effect and mechanism of Yinchenhao Decoction in preventing lipid metabolic disturbance for rats fed on high fat diet. China J Tradit Chin Med Pharm 26: 2428-2430, 2011 (In Chinese).

26. Lv J, Jin S, Yuan H, Han J, Fu S, Jin S, Guo JJ and Xiao X: Rational daily administration times of yinchenhao decoction in rats with jaundice based on PD/PK. Chin Herb Med 4: 150-156, 2012.

27. Yi YX, Ding Y, Zhang Y, Ma NH, Shi F, Kang P, Cai ZZ and Zhang T: Yinchenhao decoction ameliorates alpha-naphthylisothiocyanate induced intrahepatic cholestasis in rats by regulating phase II metabolic enzymes and transporters. Front Pharmacol 9: 510,2018

28. Wang X, Sun H, Zhang A, Jiao G, Sun W and Yuan Y: Pharmacokinetics screening for multi-components absorbed in the rat plasma after oral administration traditional Chinese medicine formula Yin-Chen-Hao-Tang by ultra performance liquid chromatography-electrospray ionization/quadrupole-time-of-flight mass spectrometry combined with pattern recognition methods. Analyst 136: 5068-5076, 2011.

29. Yan J, Xie G, Liang C, Hu Y, Zhao A, Huang F, Hu P, Liu P, Jia W and Wang X: Herbal medicine Yinchenhaotang protects against $\alpha$-naphthylisothiocyanate-induced cholestasis in rats. Sci Rep 7: 4211, 2017.

30. Cheng L, Huang C and Chen Z: Tauroursodeoxycholic acid ameliorates lipopolysaccharide-induced depression like behavior in mice via the inhibition of neuroinflammation and oxido-nitrosative stress. Pharmacology 103: 93-100, 2019.

31. National Research Council: Committee for the Update of the Guide for the Care and Use of Laboratory Animals: Association for Assessment and Accreditation of Laboratory Animal Care. In: Guide for the Care and Use of Laboratory Animals. Washington DC, 2011.

32. Committee IACaU: Institutional animal care and use committee guidebook. In: Office of Laboratory Animal Welfare. National Institutes of Health, Bethesda, MD, 2002.

33. Wang Q, Jiao L, He C, Sun H, Cai Q, Han T and Hu H: Alteration of gut microbiota in association with cholesterol gallstone formation in mice. BMC Gastroenterol 17: 74, 2017.

34. Reagan-Shaw S, Nihal M and Ahmad N: Dose translation from animal to human studies revisited. FASEB J 22: 659-661, 2008.

35. Akiyoshi T, Uchida K, Takase H, Nomura Y and Takeuchi N: Cholesterol gallstones in alloxan-diabetic mice. J Lipid Res 27: 915-924, 1986

36. Carey MC: Critical tables for calculating the cholesterol saturation of native bile. J Lipid Res 19: 945-955, 1986.

37. Livak KJ and Schmittgen TD: Analysis of relative gene expression data using real-time quantitative PCR and the 2(-Delta Delta $\mathrm{C}(\mathrm{T})$ ) method. Methods 25: 402-408, 2001

38. Portincasa P, Di Ciaula A, de Bari O, Garruti G, Palmieri VO and Wang DQ: Management of gallstones and its related complications. Expert Rev Gastroenterol Hepatol 10: 93-112, 2016

39. Shabanzadeh DM: Incidence of gallstone disease and complications. Curr Opin Gastroenterol 34: 81-89, 2018

40. Di Ciaula A, Wang DQ, Wang HH, Bonfrate L and Portincasa P: Targets for current pharmacologic therapy in cholesterol gallstone disease. Gastroenterol Clin North Am 39: 245-264, viii-ix, 2010.

41. Di Ciaula A, Wang DQ, Bonfrate L and Portincasa P: Current views on genetics and epigenetics of cholesterol gallstone disease. Cholesterol 2013: 298421, 2013.

42. Simonsen MH, Erichsen R, Froslev T, Rungby J and Sorensen HT: Postmenopausal estrogen therapy and risk of gallstone disease: A population-based case-control study. Drug Saf 36: 1189-1197, 2013. 
43. Lammert F, Gurusamy K, Ko CW, Miquel JF, Méndez-Sánchez N, Portincasa P, van Erpecum KJ, van Laarhoven CJ and Wang DQ: Gallstones. Nat Rev Dis Primers 2: 16024, 2016.

44. Di Ciaula A, Wang DQ and Portincasa P: An update on the pathogenesis of cholesterol gallstone disease. Curr Opin Gastroenterol 34: 71-80, 2018.

45. Di Ciaula A, Garruti G, Frühbeck G, De Angelis M, de Bari O, Wang DQ, Lammert F and Portincasa P: The role of diet in the pathogenesis of cholesterol gallstones. Curr Med Chem 26: 3620-3638, 2019.

46. Lavoie JM: Dynamics of hepatic and intestinal cholesterol and bile acid pathways: The impact of the animal model of estrogen deficiency and exercise training. World J Hepatol 8: 961-975, 2016.

47. Chen LY, Qiao QH, Zhang SC, Chen YH, Chao GQ and Fang LZ: Metabolic syndrome and gallstone disease. World J Gastroenterol 18: 4215-4220, 2012.

48. Han T, Zhang D, Fu Z, Sun Y, Yang W and Yuan C: Retinol-binding protein 4 as a risk factor for cholesterol gallstone formation. Mol Cell Biochem 377: 219-227, 2013.

49. Andreotti G, Chen J, Gao YT, Rashid A, Chang SC, Shen MC, Wang BS, Han TQ, Zhang BH, Danforth KN, et al: Serum lipid levels and the risk of biliary tract cancers and biliary stones: A population-based study in China. Int J Cancer 122: 2322-2329, 2008.

50. Atamanalp SS, Keles MS, Atamanalp RS, Acemoglu H and Laloglu E: The effects of serum cholesterol, LDL, and HDL levels on gallstone cholesterol concentration. Pak J Med Sci 29: 187-190, 2013.

51. Zhang S, Zhang W, Shi L, Xie A, Shao Y, Ye Y, Pan X, Lin Z, $\mathrm{Li} \mathrm{X}$ and Zhang Y: Hepatic CXCL16 is increased in gallstone accompanied with liver injury. Eur J Clin Invest 47: 667-674, 2017.

52. Makino A, Hullin-Matsuda F, Murate M, Abe M, Tomishige $N$ Fukuda M, Yamashita S, Fujimoto T, Vidal H, Lagarde M, et al: Acute accumulation of free cholesterol induces the degradation of perilipin 2 and Rab18-dependent fusion of ER and lipid droplets in cultured human hepatocytes. Mol Biol Cell 27: 3293-3304, 2016.

53. Liu C, Sun M, Wang L, Wang G, Chen G, Liu C and Liu P: Effects of Yinchenhao Tang and related decoctions on DMN-induced cirrhosis/fibrosis in rats. Chin Med 3: 1, 2008.

54. Jiang SL, Hu XD and Liu P: Immunomodulation and liver protection of Yinchenhao decoction against concanavalin A-induced chronic liver injury in mice. J Integr Med 13: 262-268, 2015

55. Yago MD, Gonzalez V, Serrano P, Calpena R, Martínez MA, Martínez-Victoria E and Mañas M: Effect of the type of dietary fat on biliary lipid composition and bile lithogenicity in humans with cholesterol gallstone disease. Nutrition 21: 339-347, 2005.

56. Morita SY,Ikeda Y, Tsuji T and Terada T: Molecular mechanisms for protection of hepatocytes against bile salt cytotoxicity. Chem Pharm Bull (Tokyo) 67: 333-340, 2019.

57. Tazuma S, Kanno K, Sugiyama A and Kishikawa N: Nutritional factors (nutritional aspects) in biliary disorders: Bile acid and lipid metabolism in gallstone diseases and pancreaticobiliary maljunction. J Gastroenterol Hepatol 28 (Suppl 4): S103-S107, 2013.

58. Vazquez MC, Rigotti A and Zanlungo S: Molecular mechanisms underlying the link between nuclear receptor function and cholesterol gallstone formation. J Lipids 2012: 547643, 2012.

59. Fracchia M, Pellegrino S, Secreto P, Gallo L, Masoero G, Pera A and Galatola G: Biliary lipid composition in cholesterol microlithiasis. Gut 48: 702-706, 2011.

60. Pasternak A, Matyja A, Gil K, Gajda M, Tomaszewski KA Gajda M, Tomaszewski KA, Matyja M, Walocha JA and Kulig J: Interstitial cajal-like cells and bile lithogenicity in the pathogenesis of gall-stone disease. Pol Przegl Chir 85: 311-316, 2013.
61. Ioannou GN, Landis CS, Jin GY, Haigh WG, Farrell GC, Kuver R, Lee SP and Savard C: cholesterol crystals in hepatocyte lipid droplets are strongly associated with human nonalcoholic steatohepatitis. Hepatol Commun 3: 776-791, 2019.

62. Zhao B, Natarajan R and Ghosh S: Human liver cholesteryl ester hydrolase: Cloning, molecular characterization, and role in cellular cholesterol homeostasis. Physiol Genomics 23: 304-310, 2005.

63. Di Ciaula A, Wang DQ, Garruti G, Wang HH, Grattagliano I, de Bari $\mathrm{O}$ and Portincasa P: Therapeutic reflections in cholesterol homeostasis and gallstone disease: A review. Curr Med Chem 21: $1435-1447,2014$

64. Hoekstra M, Van Berkel TJ and Van Eck M: Scavenger receptor BI: A multi-purpose player in cholesterol and steroid metabolism. World J Gastroenterol 16: 5916-5924, 2010.

65. Stender S, Frikke-Schmidt R, Nordestgaard BG and Tybjaerg-Hansen A: The ABCG5/8 cholesterol transporter and myocardial infarction versus gallstone disease. J Am Coll Cardiol 63: 2121-2128, 2014.

66. Dikkers A and Tietge UJ: Biliary cholesterol secretion: More than a simple ABC. World J Gastroenterol 16: 5936-5945, 2010.

67. Stokes CS and Lammert F: Transporters in cholelithiasis. Biol Chem 393: 3-10, 2012

68. Xie M, Kotecha VR, Andrade JDP, Fox JG and Carey MC: Augmented cholesterol absorption and sarcolemmal sterol enrichment slow small intestinal transit in mice, contributing to cholesterol cholelithogenesis. J Physiol 590: 1811-1824, 2012.

69. Wang LJ and Song BL: Niemann-Pick C1-Like 1 and cholesterol uptake. Biochim Biophys Acta 1821: 964-972, 2012.

70. Yoon JH, Choi HS, Jun DW, Yoo KS, Lee J, Yang SY and Kuver R: ATP-binding cassette sterol transporters are differentially expressed in normal and diseased human gallbladder. Dig Dis Sci 58: 431-439, 2013.

71. Wang LJ, Wang J, Li N, Ge L, Li BL and Song BL: Molecular characterization of the NPC1L1 variants identified from cholesterol low absorbers. J Biol Chem 286: 7397-7408, 2011.

72. Zhou X, Seto SW, Chang D, Kiat H, Razmovski-Naumovski V, Chan K and Bensoussan A: Synergistic effects of Chinese herbal medicine: A comprehensive review of methodology and current research. Front Pharmacol 7: 201, 2016

73. Zhang A, Sun H, Qiu S and Wang X: Advancing drug discovery and development from active constituents of yinchenhao tang, a famous traditional Chinese medicine formula. Evid Based Complement Alternat Med 2013: 257909, 2013.

74. Cai FF, Wu R, Song YN, Xiong AZ, Chen XL, Yang MD, Yang L, Hu Y, Sun MY and Su SB: Yinchenhao decoction alleviates liver fibrosis by regulating bile acid metabolism and TGF- $\beta /$ Smad/ERK signalling pathway. Sci Rep 8: 15367, 2018.

75. Mase A, Makino B, Tsuchiya N, Yamamoto M, Kase Y, Takeda S and Hasegawa T: Active ingredients of traditional Japanese (kampo) medicine, inchinkoto, in murine concanavalin A-induced hepatitis. J Ethnopharmacol 127: 742-749, 2010.

76. Chen SD, Fan Y and Xu WJ: Effects of yinchenhao decoction for non-alcoholic steatohepatitis in rats and study of the mechanism. J Tradit Chin Med 31: 220-223, 2011.

77. Li Y, Pan H, Li X, Jiang N, Huang L, Lu Y and Shi F: Role of intestinal microbiota-mediated genipin dialdehyde intermediate formation in geniposide-induced hepatotoxicity in rats. Toxicol Appl Pharmacol 377: 114624, 2019.

This work is licensed under a Creative Commons

Attribution-NonCommercial-NoDerivatives 4.0 International (CC BY-NC-ND 4.0) License. 